\title{
A PERGUNTA PELA IDENTIDADE PROFISSIONAL DO SERVIÇO SOCIAL: UMA MATRIZ DE ANÁLISE
}

\author{
THE QUESTION ABOUT PROFESSIONAL IDENTITY OF SOCIAL WORK: MATRIX \\ OF ANALYSIS
}

Maria Lúcia Martinelli ${ }^{1}$

\begin{abstract}
RESUMO
Apresento, neste ensaio, uma reflexão sobre a categoria identidade como um recurso heurístico para análise da natureza da profissão e sua particularidade histórica. Destaco a importância da análise de conjuntura como um caminho crítico para o desvendamento das tramas da realidade, na qual a profissão se concretiza. Finalizo apresentando a pergunta pela identidade como matriz de análise, capaz de subsidiar a leitura crítica da realidade e os processos de construção de identidades sintonizadas com as demandas contemporâneas.
\end{abstract}

PALAVRAS CHAVE: Identidade. Análise de Conjuntura. Processo Histórico. Serviço Social.

\begin{abstract}
I present, in this essay, a reflection about the class identity as a heuristic resource for the analyzing of the nature of profession and it's historical particularity. I highlight the importance of conjuncture analysis as a critical path for the unveiling of the plots of reality, in which the profession comes into being. I conclude by presenting the question for identity as matrix of analysis, capable of supporting a critical reading of the reality and the processes of identity construction in tune with the contemporary demands.
\end{abstract}

KEYWORDS: Identity. Conjuncture Analysis. Historical Process. Social Work.

\section{INTRODUÇÃO}

\section{A categoria identidade: uma primeira aproximação conceitual}

A categoria identidade é um recurso heurístico, um ancoradouro para refletir-se sobre a natureza das profissões e sua particularidade histórica.

Sob o ponto de vista dialético, a identidade é uma categoria sócio histórica que pulsa com o tempo e com o movimento, a partir de determinações políticas, sociais, econômicas, históricas, culturais. Como categoria ético-política, cujo corolário natural é

\footnotetext{
${ }^{1}$ Doutora em Serviço Social, docente, pesquisadora e coordenadora do Núcleo de Estudos e Pesquisa sobre Identidade do Programa de Estudos Pós-Graduados em Serviço Social da Pontifícia Universidade Católica de São Paulo.

Serv. Soc. \& Saúde, Campinas, SP v. 12, n 2 (16), p. 145-156, jul./dez. 2013 ISSN 1676-6806
} 
a consciência, a identidade constrói-se no fértil terreno da diferença, no interior de relações sociais antagônicas.

A construção/reconstrução críticas das identidades, como processo de identificação em curso, como permanente movimento, relação e busca, exige:

- Leitura ético-política da realidade;

- Desvendamento crítico das forças sociais em presença;

- Ações efetivas que deem concretude e materialidade às formas de ser/aparecer da profissão.

Assim sendo, mais do que perguntar por identidade devemos nos perguntar por identidades, por processos de identificação em curso, pois as identidades são, fundamentalmente, condição de ser e possibilidade, são permanências, e são transformações.

As identidades se constroem e se objetivam na práxis, pela mediação das formas sociais de aparecer das profissões. Tais formas sociais expressam as respostas construídas profissionalmente para atender às demandas que incidem em seu campo de ação.

Condensam largos percursos identitários, longas trajetórias históricas de diferenciação e reconhecimento. Expressam modos de ser e estar da profissão no confronto entre igualdade e diferença, entre diferenciação e reconhecimento. São sínteses, sempre provisórias porque históricas, de múltiplas identificações. Afinal, assim como as pessoas, as identidades nunca estão prontas, transformam-se, assim como se transformam também as condições sócio históricas em que se deu a sua construção. Tal afirmativa apoia-se em uma concepção de profissão na perspectiva sócio histórica, cujos fundamentos são:

1. A profissão é uma construção social essencialmente dinâmica, que se transforma ao se transformarem as condições em que se deu a sua construção;

2. O Serviço Social é uma profissão de natureza interventiva, especialização do trabalho coletivo, socialmente construído e partícipe do processo global de trabalho;

3. Há uma dimensão constitutiva e constituintemente política de seu processo de trabalho, como forma peculiar de intervenção no campo das relações sociais, a partir de determinações ético-políticas e socioculturais;

4. A instrumentalidade é uma condição imanente à intervenção profissional, os instrumentos são construídos e reconstruídos à luz de intencionalidades;

5. A particularidade histórica do Serviço Social é a forma de ser da profissão, a Serv. Soc. \& Saúde, Campinas, SP v. 12, n 2 (16), p. 145-156, jul./dez. 2013 ISSN 1676-6806 
forma peculiar de realização de seu processo de trabalho, com vistas à emancipação social dos sujeitos com os quais atua;

6. O trabalho profissional é o modo de ser/aparecer socialmente da profissão, é o conjunto das respostas socialmente construídas para responder às demandas que incidem em seu campo de ação;

7. A identidade é a expressão material e concreta da forma de ser da profissão, portanto é uma condição de ser, é um campo aberto de possibilidades.

\section{DESENVOLVIMENTO}

\subsection{A NATUREZA DA PERGUNTA PELA IDENTIDADE}

A pergunta pela identidade é uma pergunta de natureza filosófica, ético-política, pelo modo de ser, e não apenas de aparecer, das profissões.

A história e a filosofia são os pilares, as bases fundantes, da pergunta pela identidade:

- A história como processo transformador da realidade.

- A filosofia como busca do saber, como um modo peculiar de olhar para o mundo.

- A identidade é, portanto, uma categoria sócio-política que se constrói no jogo de forças sociais:

- Como síntese dialética entre modos de ser e de aparecer socialmente das profissões, expressando as respostas construídas profissionalmente, em diferentes momentos históricos, para atender às demandas que incidem em seu campo de ação;

- Como expressão da dimensão ético-política das profissões;

- Como elemento definidor da participação das profissões na divisão social do trabalho e na totalidade do processo social.

A perspectiva sócio histórica, ou histórico-crítica, é crucial para a formulação da pergunta pela identidade. Na verdade, é o modo necessário de realizar esta indagação: como categoria histórica, a identidade só pode ser desvendada dialeticamente na própria história. Para tanto, torna-se indispensável a busca de interpretação da realidade, a partir do desvendamento de suas múltiplas determinações: sociais, políticas, econômicas, históricas, culturais. 
As relações estrutura, conjuntura, cotidiano instituem-se como formas de acesso às múltiplas determinações da realidade, pela mediação dos contextos, acontecimentos, atores, forças sociais em presença, os quais podem ser alcançados pela análise de conjuntura como um recurso metodológico para apreender dialeticamente o movimento do real e penetrar em suas tramas constitutivas. Assim sendo, vale uma pequena digressão para melhor situar a análise de conjuntura.

Análise de conjuntura é uma leitura crítica da realidade, uma leitura especial e profunda da mesma, que se faz sempre em função de uma finalidade. É sempre uma ação intencional e complexa, de natureza eminentemente política, através da qual procura-se desvendar o real, penetrando nas suas tramas constitutivas, de forma a identificar a relação de forças que aí se processa e o fundamento crítico dessa relação.

Como o jogo de forças sociais se constrói no processo histórico, analisar a conjuntura exige penetrar na história, buscando compreender, tão profundamente quanto possível, fatos, situações, representações e tendências que permitem a construção de uma visão abrangente e crítica da realidade.

A análise de conjuntura é, então, uma leitura crítica, histórica, política e interpretativa do real, que tem por objetivo aprofundar o conhecimento sobre determinada situação ou processo social, de forma a subsidiar a tomada de decisões quanto às alternativas e estratégias a serem acionadas, tendo em vista a intervenção naquela realidade.

É um recurso analítico que se move entre estrutura e processo histórico. A estrutura é a representação formal e aparente da organização política, social e econômica de um povo, e a conjuntura é a sua expressão viva e dinâmica, variando de acordo com circunstâncias históricas, tempo e lugar.

Como expressão da estrutura, a conjuntura é tão complexa quanto ela própria, razão pela qual a realização da análise de conjuntura exige a utilização de categorias (subdimensões da realidade) e de indicadores de análise (índices da realidade).

Além do conhecimento, a análise de conjuntura, como leitura interpretativa que é, exige a capacidade de perceber criticamente, de construir nexos de articulação, de fazer interpretações e atribuir significados. O olhar político (SARLO, 2005, p. 55) é indispensável para tanto, pois possibilita desvendar as tramas constitutivas do real.

Como a conjuntura é uma representação do processo social, uma expressão da estrutura, as principais categorias a serem trabalhadas para analisá-la são fundamentalmente sociais, são “representações da vida”, como as denominou o cientista social Her- 
bert de Souza, em sua clássica produção intitulada "Como se faz análise de conjuntura" (1984, p. 9).

Tomando por referência a matriz teórica por ele legada, as principais categorias a serem trabalhadas para realização de análise de conjuntura são: acontecimentos, cenários, atores, relação de forças, articulação entre estrutura e conjuntura.

Acontecimentos: são fatos que pelo impacto que produzem, e pelas consequências que acarretam para o conjunto da sociedade, adquirem sentido especial no curso do processo histórico.

Identificar os principais acontecimentos em um determinado momento histórico, atribu-ir-lhes graus variados de importância conforme o impacto que produzem, estabelecer nexos de articulação entre os mesmos e em relação à estrutura social, são operações fundamentais para a análise de conjuntura. Além de permitirem uma caracterização da conjuntura, os acontecimentos são reveladores de tendências presentes no jogo de forças sociais.

Contextos: são os espaços societários onde se desenvolvem as tramas sociais e políticas. Identificar e conhecer criticamente estes contextos é fundamental para a análise de conjuntura, pois são expressões da organização política e social de uma dada realidade.

Atores sociais: são todos os elementos que participam de uma trama de relações: pessoas, grupos, movimentos sociais e instituições. Na análise de conjuntura, o importante é descobrir que papel desempenham e que peso têm na correlação de forças vigente.

Relação de forças: as classes sociais, os grupos, os diferentes atores sociais estão em permanente relação uns com os outros. Estas relações podem ser de confronto, de coexistência, de cooperação e estão sempre revelando uma tendência, seja de dominação, de subordinação, de igualdade. A identificação da relação de forças, e das tendências presentes no contexto social, é fundamental para a análise de conjuntura, até mesmo porque esta relação é profundamente dinâmica, alterando-se permanentemente em função do próprio processo histórico e de estrutura social.

Articulação entre estrutura e conjuntura: os acontecimentos, as ações desenvolvidas pelos atores sociais nos diferentes cenários, não se dão no vazio. Têm relação com a história, com as relações políticas, sociais e econômicas, com a forma de organização social, enfim, com a estrutura. Realizar análise de conjuntura exige esta construção permanente de nexo de articulação entre estrutura e conjuntura, entre conjuntura e cotidiano, de compreensão 
crítica da relação entre fatos, acontecimentos e atores em um determinado tempo e lugar históricos.

Como ação política que alimenta decisões igualmente políticas, a análise de conjuntura busca sempre produzir intervenções na estrutura social. Na verdade, seu valor se encontra exatamente no potencial de transformação da realidade de que é portadora. Não há, porém, uma análise de conjuntura unívoca, pois a leitura da realidade depende sempre de quem a lê, e dos objetivos com que o faz. Há, portanto, visões plurais de conjuntura. O que se espera, e daí a importância de se trabalhar com categorias e indicadores, é que mesmo na pluralidade, a intencionalidade maior seja sempre a de transformar o real, a de produzir o novo.

Um apoio importante para bem realizar a análise de conjuntura, além do acurado olhar político, é a leitura da realidade em uma perspectiva crítica, conforme a denomi-nou Ianni (1988, p. 9), com base na produção marxiana. As peculiaridades dessa análise segundo este autor são apresentadas na sequência:

1. É uma análise que adere criticamente ao objeto, compreendendo-o e negando-o simultaneamente;

2. Interpreta criticamente o real, interrogando-o a partir de perguntas radicais;

3. Realiza-se através de um exercício de reflexão prático-crítico, buscando soluções novas e revolucionárias para os problemas que enfrenta;

4. Procura compreender todas as circunstancialidades temporais, materiais e históricas que impregnam o objeto;

5. Penetra nas tramas do real, buscando desvendá-las pacientemente, para entender as relações constitutivas de seu objeto;

6. Trabalha permanentemente com o sujeito como ser social, histórico, em seu viver cotidiano, procurando conhecer tão plenamente quanto possível sua experiência social (sentimentos, valores, crenças, afetos, representações);

7. Realiza uma interpretação verdadeiramente radical de seu objeto, a qual no momento mesmo em que se produz, transforma-se em força social decisiva (trata-se, portanto, de uma análise prático-crítica);

8. É uma análise que vai à raiz do problema e que propõe soluções novas e radicais (superações, portanto, de modo prático-crítico). Ser radical, nesta perspectiva, é atacar o problema pela raiz. E a raiz para o Serv. Soc. \& Saúde, Campinas, SP v. 12, n 2 (16), p. 145-156, jul./dez. 2013 ISSN 1676-6806 
homem, é o próprio homem.

É inegável, porém, que há pelo menos duas grandes perspectivas que orientam as análises de conjuntura no Brasil:

- Uma que se apoia na lógica do poder e que realiza suas leituras a partir da ótica das classes dominantes. De modo geral as análises produzidas por essa vertente, tendem a ser conservadoras, enfatizando mecanismos de reordenação dos elementos da realidade, sem que haja alteração substantiva dos mesmos.

- Outra que realiza suas leituras a partir das demandas e necessidades das classes populares, das reivindicações e buscas dos movimentos sociais. As análises produzidas nessa perspectiva enfatizam ações transformadoras da realidade, procurando levantar alternativas e possibilidades que permitam o atendimento das aspirações da grande maioria da população.

O compromisso do trabalhador social com as classes populares, sem dúvida, está direcionado para essa segunda vertente, pois aí é que se encontra o sentido de sua prática, a direção social presente no projeto ético-político de profissão.

\section{CONCLUSÃO: A PERGUNTA PELA IDENTIDADE COMO MATRIZ DE ANÁLISE}

A pergunta pela identidade é uma pergunta de natureza ontológica que remete a pensar não apenas no que as profissões são, mas como aparecem socialmente e como participam do processo de reprodução social.

Nesse sentido é que afirmamos, como Oliveira, (1987, p. 13) que, identidades não são meros processos de reposição ou de reiteração, ao contrário, são construções sócio-políticas que pulsam com o tempo e com o movimento, a partir de determinações políticas, sociais, econômicas, históricas e culturais.

A pergunta pela identidade é, pois, uma pergunta de natureza histórica, dialética, que sintetiza/articula dialeticamente o que somos, a forma de ser de profissão, o que fazemos, a forma pela qual a profissão aparece socialmente, ou seja, o conjunto de intervenções que realiza em um dado momento histórico, e o que aspiramos fazer a partir das determinações ético-políticas de nosso projeto profissional e dos desafios e demandas que emergem da realidade cotidiana. 
Há uma profunda interação entre as identidades construídas e atribuídas, pois as identidades profissionais não são dadas, mas sim construídas em um complexo jogo de forças sociais, no contexto de nossa existência humana.

Os processos de construção/reconstrução de identidades, como processos de identificação em curso, se dão em meio a relações antagônicas, em meio a relações de poder que atravessam a sociedade e que se explicitam nas práticas profissionais que realizamos. Tais práticas movimentam saberes, saberes estes que não tem apenas nexos lógicos, mas também políticos, instituindo-se “como arma contra o poder”, (SEVERINO, 1995, p. 53) como possibilidade concreta de subsidiar processos de construção de identidades.

Nesta concepção de profissão na perspectiva sócio histórica saber, poder e fazer são dimensões constitutivas da prática humana, são mediações da prática profissional na qual se articulam organicamente:

- Dimensões ético-políticas, referidas ao campo do poder;

- Teórico-metodológicos ao campo do saber;

- Técnico-operativas ao campo do fazer, e que estão sempre referidas ao fim último da ação profissional, que articula estas dimensões e configura a particularidade histórica da profissão, posicionando-a sempre no campo dos direitos e na busca da emancipação social dos sujeitos com os quais atuamos.

As identidades, por sua natureza essencialmente dinâmica, criam-se e recriam-se continuamente no fértil terreno das diferenças, das diversidades, num verdadeiro jogo dialético, onde pulsam identidades construídas e atribuídas.

As primeiras, compreendidas como sínteses dialéticas entre modos de ser e de aparecer socialmente das profissões, as segundas como identidades que decorrem de circuitos externos às próprias profissões.

Explicita-se aí o caráter dialético das identidades atribuídas, pois até mesmo para serem atribuídas em algum momento foram construídas, expressando as condições concretas daquele momento histórico.

Com base em Lukács (1989, p. 13), é possível admitir-se um caráter dialético na própria noção de “falsidade” da consciência, ou da identidade. Não como oposição ao verdadeiro, mas como "momento da totalidade histórica a que pertence, como etapa do processo histórico onde representa seu papel” (ibid., p. 63). 
É imperioso reconhecer a importância do vigor ético-político da categoria profissional e do lugar social que ocupa no conjunto das profissões e no contexto societário mais amplo, no sentido de lutar coletivamente pela construção de identidades sintonizadas com o momento histórico, que apareçam socialmente pela mediação de práticas consistentes, rigorosas, politicamente valiosas e como tais reconhecidas socialmente.

O exercício profissional se dá em meio a identidades construídas e atribuídas, sendo de fundamental importância a leitura ético-político da realidade e do próprio cotidiano, tendo em vista o desvendamento das forças sociais em presença para a realização de uma prática profissional crítica, competente, direcionada para o fortalecimento de identidades historicamente construídas.

Finalizando, vale ressaltar que pensar as profissões a partir de uma perspectiva ético-politica, e visualizá-las a partir do marco de sua identidade, pressupõe considerálas como construções sociais essencialmente dinâmicas, que se transformam, como se transformam as condições em que se deu a sua construção histórica, o que exige dos profissionais um permanente exercício crítico de leitura da realidade.

\section{REFERÊNCIAS}

DUBAR, C. A socialização. A construção das identidades sociais e profissionais. Trad. Annette. P. R. Botelho e Estela P. Lamas. Portugal: Porto Editora, 1997. IANNI, O. Dialética e Capitalismo. Ensaio sobre o pensamento de Marx. $3^{\text {a }}$ Ed. Petrópolis: Vozes. 1988.

GRAMSCI, A. Alguns temas da questão meridional. Temas de Ciências Humanas, nº 1 . Trad. Marco Aurélio Nogueira. São Paulo, Ciências Humanas, 1977.

LUKÁCS, G. História e consciência de classe. Trad. Telma Costa. Portugal, Biblioteca Ciência e Sociedade. Publicações Escorpião, 1974.

MARTINELLI, M. L. Aliança e consenso no Serviço Social: algumas reflexões à luz da perspectiva gramsciana. Serviço Social \& Sociedade. No 22. São Paulo, Cortez, 1987. MARTINELLI, M. L. et al. (Orgs). O uno e o múltiplo nas relações entre as áreas do saber. São Paulo, Cortez, 1995.

MARTINELLI, M. L. O uno e o múltiplo: relações entre as áreas do saber: uma abordagem sócio educacional. In: MARTINELLI, M. L. et alii (Orgs). O uno e múltiplo nas relações entre as áreas do saber. São Paulo: Editora Cortez, 1995.

MARTINELLI, M. L. A nova identidade profissional. Serviço Social Hospitalar, vol. Serv. Soc. \& Saúde, Campinas, SP v. 12, n 2 (16), p. 145-156, jul./dez. 2013 ISSN 1676-6806 
4, n 1/97. p. 21-25. São Paulo. Coordenadoria do Hospital das Clínicas, FMUSP. 1997. MARTINELLI, M. L. Desafios do Serviço Social na transição para o próximo milênio. Serviço Social \& Sociedade, ano XIX, nº 57, São Paulo, Cortez, p. 133-148, jul. 1998. MARTINELLI, M. L. Sentido e direcionalidade da ação profissional. In: BAPTISTA, M. V.; BATTINI, O. A prática profissional do Assistente Social: teoria, ação, construção de conhecimento. Volume I. São Paulo: Veras Editora, 2009, p. 149-158

MARTINELLI, M. L. Pensar a identidade: eis a tarefa. Um ensaio sobre a identidade profissional do Serviço Social v. II, KARSCH, U. (Org). Estudos do Serviço Social: Brasil e Portugal. São Paulo: EDUC. 2005, p. 65-78.

MARTINELLI, M. L. Reflexões sobre o Serviço Social e o projeto ético-político profissional. Emancipação. Paraná. Ponta Grossa. Nº 6 (VI), p. 9-23, maio, 2006.

MARTINELLI, M. L. O exercício profissional do assistente social na área da Saúde: Algumas reflexões éticas. Serviço Social \& Saúde. São Paulo: UNICAMP, v. 6, (VI) p. 21-34, maio, 2007.

MARTINELLI, M. L. Serviço Social: Identidade e alienação. 13ª edição. São Paulo: Cortez, 2009.

MARX, K.; ENGELS, F. A ideologia alemã (I - Feuerbach). Trad. José Carlos Bruni e Marco Aurélio Nogueira. São Paulo: HUCITEC. 1984

MARX, K. As lutas de classe na França (1848-1850). São Paulo: Global, 1986.

MARX, K. O dezoito Brumário de Louis Bonaparte. Trad. Silvio Donizete Chagas. São Paulo: Moraes, 1987.

OLIVEIRA, F. de. O elo perdido. Classe e identidade de classe. São Paulo: Brasiliense, 1987.

SARLO, B. Um olhar político, paisagens imaginárias: intelectuais, arte e meios de comunicação: Tradução Rubia Prates Goldoni e Sérgio Molina. $1^{\text {a }}$ edição, $1^{\text {a }}$ reimpressão. São Paulo: Editora da Universidade de São Paulo, 2005.

SAWAYA, B. Identidade: uma ideologia separatista? SAWAYA, B. et alii (Orgs.) As artimanhas da exclusão. Análise psicossocial e ética da desigualdade social. $6^{\text {a }}$ ed. Petrópolis, Editora Vozes, 2006, p. 119-128.

SAWAYA, B. O sofrimento ético-político como categoria de análise da dialética exclusão/inclusão. SAWAYA, B. et al. (Orgs). As artimanhas da exclusão. Análise psicossocial e ética da desigualdade social. 6ª Ed. Petrópolis: Editora Vozes, 2006, p. 97-118. 
SEVERINO, A. J. O poder e a verdade do saber. In: MARTINELLI, M. L. et al. (Orgs). O uno e o múltiplo nas relações entre as áreas do saber. São Paulo: Cortez, 1995, p. 46-54.

SOUZA, H. J. de. Como se faz análise de conjuntura. Petrópolis: Vozes, 1984.

YAZBEK, M. C. Classes Subalternas e Assistência Social. São Paulo: Cortez, 1993.

YAZBEK, M. C.; MARTINELLI, M. L.; RAICHELIS, R. Serviço Social brasileiro em movimento. Fortalecendo a profissão na defesa dos direitos. Serviço Social \& Sociedade. São Paulo: Cortez. N. 98, p. 5-32, set. 2008. 